\title{
Características fisicoquímicas y microbiológicas de yogur a partir de colorante de remolacha (Beta vulgaris L.) encapsulado
}

\author{
Physicochemical and microbiological characteristics of yoghurt from beetroot colorant \\ encapsulated
}

Parra H. Ricardo

Docente investigador, Universidad Pedagógica y Tecnológica de Colombia. Química de alimentos. Avenida central del norte. Tunja. Colombia.

\section{RESUMEN}

${ }^{*}$ Autor a quien debe dirigirse la correspondencia. E-mail: ricardo.parra@uptc.edu.co

Palabras clave: Color, encapsulación, remolacha, yogur. 


\begin{abstract}
The objective of this study was to encapsulate coloring beetroot by the extrusion method and determine its effect on the addition of yogurt. Beetroot was used for this experiment. A batch of yogurt was prepared and this was divided into two treatments, the first one was added $0.6 \%$ dye encapsulated capsules containing $2 \%$ of sodium alginate, the second treatment no capsules was added. Each of the treatments $\mathrm{pH}$, acidity, syneresis, lactic acid bacteria count and visual monitoring for 9 days was evaluated. The results indicated that the capsule and gradually released dye was used as an energy source by the lactic acid bacteria slightly increasing the bacterial count, the acidity increased and $\mathrm{pH}$ values decreased. Statistically no significant differences in the two treatments for $\mathrm{pH}$ and acidity were found; otherwise occurred with syneresis presenting significant differences. The encapsulation technique used as for the encapsulation beetroot was feasible for 9 days during yogurt storage; $\mathrm{pH}$, acidity and lactic acid bacterial count had similar behavior for a yogurt without capsules.
\end{abstract}

Keywords: Color, encapsulation, beetroot, yogurt.

\title{
INTRODUCCIÓN
}

El color natural de los alimentos se debe principalmente a los carotenoides, antocianinas, betalaínas y clorofilas, ya sea en la comida como inherente constituyente de los alimentos o como aditivos alimenticios. Estos componentes han llamado la atención en los últimos años, no solo por sus propiedades de colorantes, si no debido a sus efectos potenciales en la salud (Rodríguez, 2016). Al respecto, un ejemplo de estos colorantes naturales es la remolacha, utilizada principalmente para la estimulación del sistema hematopoyético e inmunológico, así como en la protección de los riñones, el hígado y el intestino. Por otra parte, la remolacha tiene actividades mineralizantes, antisépticas, coleréticas y contribuye al reforzamiento de la mucosa gástrica, además, ha sido utilizada para la terapia de tumores intestinales y tumores genitales, mientras que los zumos de raíces frescas o las hojas han sido considerados efectivos en la terapia de tumores del sistema digestivo, así como del pulmón, hígado, mama, próstata y útero (Ninfali y Angelino, 2015), anemia y convalecencia debido a su alto contenido de hierro (Casierra y Pinto, 2011; Soriano et al., 2007).
De otro lado, la encapsulación es un técnica por la cual, gotas liquidas, partículas sólidas o gaseosas son cubiertas con una película polimérica porosa conteniendo una sustancia activa (Parra, 2010).

Según Parra (2010) y Astray et al., (2009), dentro de un proceso de encapsulación se puede encontrar las siguientes ventajas:

- Proteger el material activo de la degradación producida por el medio ambiente (calor, aire, luz, humedad), etc.

-Liberación gradual del compuesto que lo ha englobado o atrapado en un punto determinado.

-Las características físicas del material original pueden ser modificadas y hacer más fácil su manejo (un material líquido convertido a polvo), la higroscopia puede ser reducida, la densidad se modifica y el material.

-El sabor y olor del material puede ser enmascarado.

-Puede ser empleado para separar componentes con el fin de que estos no reaccionen.

-Estabilización de principios activos inestables.

-Transformación de líquidos en sólidos 
De los varios métodos para encapsular, la extrusión es el método más antiguo y común para elaborar cápsulas con adición de sustancias, esta técnica consiste en la caída de solución de alginato concentrado por lo general a través de una aguja dentro de una solución de cloruro de calcio ocurriendo así una gelificación (Cook et al., 2012). El tamaño y la forma de las cápsulas dependen del diámetro de la aguja y la distancia de caída libre respectivamente. Este método es el más popular debido a su facilidad, simplicidad, bajo costo y condiciones de formulación (Krasaekoopt et al., 2003).

El yogur es uno de los derivados lácteos más populares del mundo, obtenido durante la fermentación láctica lenta de la lactosa de la leche por bacterias acido lácticas (Zare et al., 2012; Ladjevardi et al., 2015). De acuerdo a las leyes de algunos países, el yogur debe contener microflora abundante y viable de valores mínimos de consumo entre 106 y 108 UFC/g (Ladjevardi et al., 2015).

Debido al aumento en la población mundial, es importante la prevención y tratamiento de enfermedades y maximizar la calidad de vida. Al respecto, se ha observado in vitro e in vivo que los productos lácteos fermentados con bacterias ácido lácticas (BAL) como el yogur tiene propiedades funcionales porque ayudan a incrementar la habilidad del cuerpo para resistir la invasión de patógenos, prevención de enfermedades urogenitales (candidal vaginitis), protección y prevención contra la diarrea, control de enfermedades inflamatorias del intestino como enfermedad de Crohn y pouchitis, síndrome del intestino irritable, alivio de los síntomas de intolerancia a la lactosa, reducción del colesterol y reducción de la presión arterial, prevención de alergias alimentarias y prevención y tratamiento de ulcera gástrica causada por Helicobacter pylori entre otros beneficios (Parra, 2012).

Teniendo en cuenta lo anterior, el objetivo de este trabajo fue evaluar las características físicas, químicas y microbiológicas de un yogur con colorante rojo de remolacha encapsulado.

\section{MATERIALES Y MÉTODOS}

Esta investigación se llevó a cabo en los laboratorios de Química de Alimentos de la Universidad Pedagógica y Tecnológica de Colombia, sede Tunja-Boyacá.

\section{Materiales}

La remolacha se obtuvo en el mercado local de la ciudad de Tunja, Colombia.

Para la elaboración de yogur se utilizó: $1 \%(\mathrm{p} / \mathrm{p})$ de un cultivo iniciador liofilizado marca Vivolac DRISET conteniendo los microorganismos Lactobacillus delbrueckii subsp. bulgaricus y Streptococcus thermophilus, leche líquida entera ultrapasterizada, leche en polvo entera y sacarosa, todas de marca nacional reconocida.

\section{Obtención del colorante a partir de remolacha}

Una vez recolectada las remolachas, fueron cuidadosamente limpiadas, peladas y cortadas en rebanadas de $10 \mathrm{~mm}$ de espesor perpendiculares a su eje, posteriormente se licuó y filtró a través de una bomba de vacío según procedimiento sugerido por Latorre et al., (2010). Posteriormente se pasterizó a $90^{\circ} \mathrm{C}$ por 10 minutos y se almacenó en refrigeración durante 24 horas hasta su utilización en la encapsulación.

\section{Encapsulación del colorante}

Se utilizó la metodología de Kumar y Singh (2007); Sultana et al., (2000) y Parra, (2014), con algunas modificaciones, donde sugirió utilizar una concentración de $0,1 \mathrm{M}$ de cloruro de calcio y $2 \%$ de alginato de calcio como agente encapsulante, la concentración empleada para encapsular fue 10\% de jugo de remolacha (previamente se realizó experimentos con concentraciones de jugo, encontrándose la más óptima la de 10\%).

\section{Elaboración de yogur}

Para la elaboración de yogur se considero la metodología de Parra, (2013). A la leche ultrapasterizada se añadió $3 \%$ de leche en polvo, 
$10 \%$ de sacarosa y $1 \%$ de cultivo iniciador. La mezcla anterior se homogenizó de manera mecánica con agitador de vidrio y llevó a una incubadora con temperatura de $45^{\circ} \mathrm{C}$ y hasta alcanzar una acidez mínima de $0,6 \%$ de ácido láctico, valor recomendado según Norma Técnica Colombiana 805. Posteriormente el lote de yogur se dividió en dos partes iguales, a la primera se añadió $0,6 \%$ de cápsulas con el colorante encapsulado, la segunda parte no sufrió modificaciones. Cada uno de los tratamientos se envasaron en recipientes de plástico asépticos con capacidad para $300 \mathrm{~mL}$ posteriormente se almacenaron en refrigeración a $4^{\circ} \mathrm{C}$. Durante el tiempo de almacenamiento se realizaron a ambos tratamientos: $\mathrm{pH}$, acidez titulable, recuento de BAL, sinéresis por duplicado y un seguimiento visual de las cápsulas. El experimento tuvo duración de 13 días, tiempo en el cual se liberó el colorante. Para cada monitoreo del día correspondiente, se utilizó una muestra de 300 $\mathrm{ml}$ de yogur de cada tratamiento la cual se desechaba después de realizar los respectivos análisis.

\section{Métodos}

Para la determinación de $\mathrm{pH}$ se utilizó un pH-metro marca oakton previamente calibrado teniendo en cuenta el método de la A.O.A.C. 31.231/90 adaptado, se determinó los días 1, 5, 9 y 13 de almacenamiento en refrigeración. Para la sinéresis se utilizó una centrífuga marca Rotina, para ello se pesaron 20 gramos de cada uno de los tratamientos de yogur y se sometieron a centrifugación por un tiempo de 20 minutos a una velocidad de $4000 \mathrm{rpm}$. Luego de la centrifugación se obtuvo los mililitros del sobrenadante (lactosuero) y se calculó el grado de sinéresis mediante la relación entre el volumen del sobrenadante y de la muestra (Charoenrein et al., 2008). El porcentaje de sinéresis fue determinado en los días $1,5,9$ y 13 bajo condiciones de refrigeración.

\section{Análisis microbiológico de bacterias ácido lácticas}

Se utilizó la metodología empleada por Kailsapathy (2006) utilizando agar MRS con algunas modificaciones. Las cajas de petri fueron incubadas anaeróbicamente por 48 horas a $37^{\circ} \mathrm{C}$. El análisis se realizó al inició y final del experimento a los dos tratamientos.

\section{Análisis estadístico}

Los resultados se analizaron estadísticamente mediante la prueba de T-student, empleando el programa de Excel $\circledast$ a un nivel de significancia del $p<0,05$ con dos réplicas.

\section{RESULTADOS Y DISCUSIÓN}

\section{pH}

El comportamiento para ambos tratamientos se presentan en la figura 1, se detalla que los valores para el yogur con cápsulas durante el estudio fueron inferiores en comparación con el yogur que no contenía cápsulas; sin embargo, al final del experimento los valores para ambos tratamientos fueron iguales 3,97. Al transcurrir los días los valores de $\mathrm{pH}$ para ambos tratamientos fueron similares entre sí. Estadísticamente no existen diferencias significativas $(p>0.05)$ entre los dos tratamientos con cápsulas y sin cápsulas. Este comportamiento se debe probablemente a que durante el almacenamiento las cápsulas liberaron lentamente el colorante proporcionando sustancias y/o compuestos del jugo de remolacha que sirvieron como fuente de energía a las BAL durante la ruta metabólica de la glucólisis, disminuyendo así el pH. Al respecto Rojas et al., (2007) explican que una vez inoculada la leche se incia una fermentacion ácido-lactica por la hidrólisis enzimatica de la lactosa en glucosa y galactosa, siendo la glucosa degradada en ácido láctico; en otros estudios realizados por Hassan y Amjad (2010), y Kailasapathy et al., (2008), también mencionan que la reducción en el $\mathrm{pH}$ del yogur puede deberse a la degradación de la lactosa en ácido láctico. Al respecto en estudios realizados por Sahan et al., (2008); Ruíz y Ramírez, (2009); Olson y Aryana, (2008), reportaron que el $\mathrm{pH}$ de yogur disminuye durante el almacenamiento en condiciones de refrigeración entre 3,8 y 4,5. 


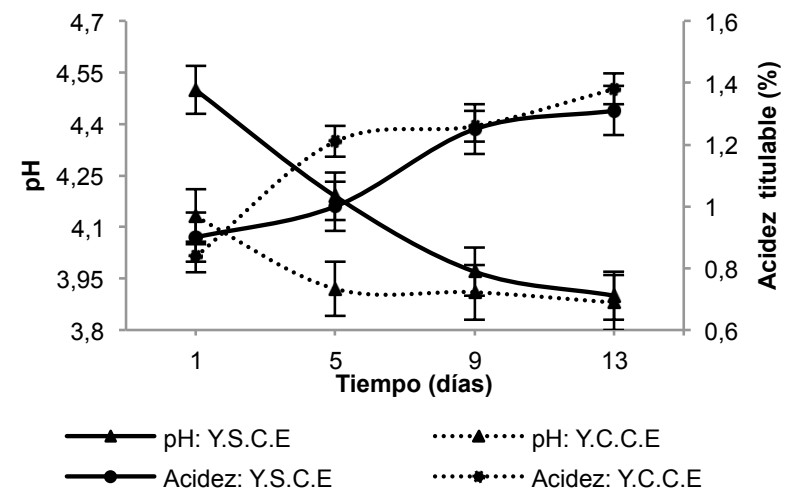

Y.S.C.E $=$ Yogur sin colorante encapsulado; Y.C.C.E= Yogur con colorante encapsulado.

Figura 1. Comportamiento de $\mathrm{pH}$ y acidez durante el almacenamiento de yogur con colorante encapsulado y yogur sin cápsulas.

\section{Sinéresis}

En la tabla 1 se observa el comportamiento de los dos tratamientos. El yogur que contenía las cápsulas con el colorante presentó valores de sinéresis de $43 \%$ al final del estudio, para el yogur que no contenía cápsulas la sinéresis final fue $30 \%$. Estadísticamente existe diferencia significativa $(p<0.05)$ en los dos tratamientos.

El comportamiento de la sinéresis para ambos tratamientos puede explicarse por la disminución en el $\mathrm{pH}$ durante el almacenamiento lo cual tuvo un efecto de contracción en la matriz de la micela de caseína causando más eliminación de lactosuero (Achanta et al., 2007). Díaz et al., 2004 reportan valores finales para sinéresis entre $45-65 \%$ para un yogur control (sin fibra, elaborado con leche entera y sacarosa), este valor coincide con el yogur sin cápsulas y yogur con colorante encapsulado.

Tabla 1

Valores de sinéresis para yogur sin cápsulas y yogur con colorante encapsulado

\begin{tabular}{ccc}
\hline \multirow{2}{*}{ Día } & \multicolumn{2}{c}{ Sinéresis (\%) } \\
\cline { 2 - 3 } & Y.C.C.E & Y.S.C.E \\
\hline 1 & $58 \pm 0,70$ & $40 \pm 0,95$ \\
5 & $49 \pm 0,21$ & $43 \pm 0,14$ \\
9 & $45 \pm 0,28$ & $31 \pm 0,70$ \\
13 & $43 \pm 0,21$ & $30 \pm 0,14$ \\
\hline $\begin{array}{l}\text { Y.S.C.E= Yogur sin colorante encapsulado; Y.C.C.E= Yogur con colorante } \\
\text { encapsulado. }\end{array}$
\end{tabular}

\section{Acidez}

En la figura 1 se observa que la acidez al final del experimento fue igual para ambos tratamientos $1,3 \%$ expresada en ácido láctico. Se observa además que la muestra de yogur que contenía cápsulas al transcurrir los días presentó mayores valores de acidez en comparación con las muestras de yogur que no las contenía. Estadísticamente no existe diferencia significativa $(p>0.05)$ en la acidez para los dos tratamientos. Lo anterior puede atribuirse a la hidrólisis realizada por las bacterias ácido lácticas del colorante liberado en el yogur, al respecto Rojas et al., (2007) describen que durante la fermentación ácido láctica, la glucosa es degrada a ácido láctico, esta glucosa podría provenir de los azúcares propios de la remolacha y estar disponibles para los microorganismos ácido lácticos, esto explicaría porque el tratamiento con el colorante encapsulado tuvo mayores valores de acidez en comparación con el tratamiento que no contenía cápsulas. Briceño et al., (2001), mencionan que durante el almacenamiento de un yogur en condiciones de refrigeración sin encapsulamiento durante un periodo de 20 días, la acidez final fue 1,0\% expresada en ácido láctico, este valor es cercano al yogur sin encapsular presentado en la figura 1. Lubbers et al., (2004), describen que cambios en la acidez en un yogur pueden atribuirse a que en el almacenamiento en condiciones de refrigeración puede ocurrir actividad microbiana.

Según el Codex Alimentarius en la norma correspondiente a leches fermentadas-yogur STAN 243-2003, y la Norma Técnica Colombiana 805, el valor de acidez debe ser mínimo 0,6\% expresado en ácido láctico, lo anterior indica que los valores de acidez titulable de los dos tratamientos reportados en la figura 1 están dentro de los valores permitidos por estas dos normas.

\section{Recuento microbiológico de bacterias ácido lácticas}

En la tabla 2 se observa que el número de unidades formadoras de colonias formadas por bacterias ácido lácticas al inicio y al final del experimento. Al comparar ambos tratamientos los recuentos iniciales y finales aumentaron; sin embargo, fue mayor en el yogur que contenía las cápsulas con el 
colorante, lo anterior indica que el colorante fue utilizado como fuente de energía para el metabolismo microbiano por parte de las BAL aumentando así las unidades formadoras de colonia al final del experimento.

Los resultados del yogur sin colorante encapsulado son similares a los presentados por Parra (2013), quien reporta un valor de $105 \mathrm{ufc} / \mathrm{g}$, para un yogur elaborado con condiciones similares. El Codex Alimentarius en la norma correspondiente a leches fermentadas-yogur STAN 243-2003 y la NTC 805 relacionado con yogur, mencionan ambas que el valor de ufc/g debe ser mínimo de 106, lo anterior indica que el yogur con colorante encapsulado cumple con la normatividad establecida según se reporta en la tabla 2.

Tabla 2

Recuento microbiológico de bacterias ácido lácticas en yogur sin cápsulas y yogur con betalaína encapsulada

\begin{tabular}{ccc}
\hline Tratamiento & \multicolumn{2}{c}{$\begin{array}{c}\text { Recuento de BAL } \\
\text { (UFC/g) }\end{array}$} \\
& Inicio & Final \\
\hline $\begin{array}{c}\text { Yogur con colorante } \\
\text { encapsulado } \\
\text { Yogur sin colorante } \\
\text { encapsulado }\end{array}$ & $2,29 \times 10^{5}$ & $1,52 \times 10^{6}$ \\
\hline
\end{tabular}

\section{Seguimiento visual}

En la figura 2 se detalla que durante el almacenamiento, las cápsulas liberan lentamente el colorante en el yogur, finalmente el día 9 de almacenamiento las cápsulas liberaron totalmente el colorante, concluyendo así el experimento. En la figura 2-a se observa la formación de las cápsulas con el colorante en la solución de cloruro de calcio. En la figura 2-b se tiene las cápsulas preparadas para ser añadidas al yogur. En la 2-c se detalla que van liberando lentamente el colorante, presentándose la liberación total el día 9, tal y como se observa en la figura 2-d.

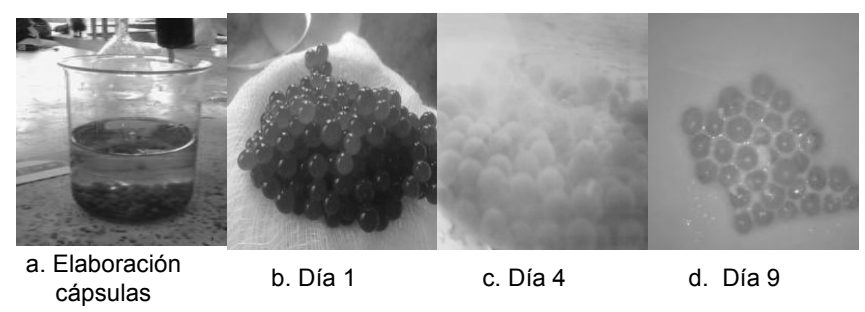

Figura 2. Seguimiento visual de las capsulas con colorante encapsulado durante el almacenamiento de yogur.

\section{CONCLUSIONES}

Se elaboró un yogur con colorante encapsulado mediante un procedimiento sencillo y repetible, esta técnica es una opción viable para el sector agroindustrial y consumidor. Los resultados indicaron que encapsulación permaneció estable durante 9 días tiempo en el cual hubo liberación del colorante, permitiendo ser fuente de energía para las BAL en el yogur, por lo tanto el recuento de estas bacterias aumentó en el yogur que contenía las cápsulas en comparación con el yogur que no las contenía; la acidez aumentó ligeramente y el pH disminuyó respecto al yogur que no contenía las cápsulas.

\section{REFERENCIAS BIBLIOGRÁFICAS}

Achanta, K.; Aryana, K.; Boeneke, C. Fat free plain set yogurts fortified with various minerals. (2007). LWT. 40:424-429.

A.O.A.C. The official and recommended practices of the American Chesmest's Society. 1990
Astray, G.; Mejuto, J.; Rial, R.; González, C and Simal, J. (2009). A review on the use of cyclodextrins in foods. Food Hydrocolloids 23(7): 1631-1640.

Briceño, A.; Martínez, R.; García, K. Viabilidad y actividad de la flora láctica (streptococcus salivarius ssp thermophilus y lactobacillus delbrueckii ssp bulgaricus) del yogurt en Venezuela. (2001). Acta Científica Venezolana 52: 46-54. 
Casierra, F.; Pinto, R. Crecimiento de Plantas de Remolacha (Beta vulgaris L. var. Crosby Egipcia) Bajo Coberturas de Color. (2011). Revista Facultad Nacional de Agronomía. Medellín 64(2): 6081-6091.

Codex Alimentarius. Directrices sobre bebidas fermentadas CODEX STAN 243.2003. Disponible en http://www.codexalimentarius.org/download/standards/400/CX S_243s.pdf [Consultado: mayo 15 2015].

Cook, M.; Tzortzis, G.; Charalampopoulos, D.; Khutoryanskiy, V. Review Microencapsulation of probiotics for gastrointestinal delivery. (2012). Journal of Controlled Release 162: 56-67.

Charoenrein, S.; Tatirat, O.; Muadklay, J. Use of centrifugationfiltration for determination of syneresis in freeze-thaw starch gels. (2008). Carbohydrate Polymers 73: 143-147.

Delgado, F.; Jiménez, A.; Paredes, O. Natural pigments: Carotenoids, anthocyanins, and betalains- characteristics, biosynthesis, processing, and stability. (2000). Crit Rev Fd Sci Nut 40: 173-289.

Díaz, B.; Sosa, M.; Vélez, R. Efecto de la adición de fibra y disminución de grasa en las propiedades fisicoquímicas del yogurt. (2004). Revista Mexicana de Ingeniería Química, 3:287-305

Hassan, A.; Amjad, I. Nutritional evaluation of yoghurt prepared by different starter cultures and their physiochemical analysis during storage. (2010). African Journal of Biotechnology 9:2913-2917.

Hussain, I.; Rahman, A.; Atkinson, N. Quality comparation of probiotic and natural yogurt. (2009). Pakistan Journal of Nutrition 8: 9-12.

NORMA TÉCNICA COLOMBIANA (NTC) 805. Productos lácteos. Leches fermentadas. ICONTEC, 2006.

Kailasapathy, K.; Harmstorf I.; Phillips, M. Survival of Lactobacillus acidophilus and Bifidobacterium animalis ssp. lactis in stirred fruit yogurts. (2008). Food Science and Technology 41:1317-1322.

Kumar, A.; Singh, $H$. Review recent advances in microencapsulation of probiotics for industrial applications and targeted delivery. (2007). Trends in Food Science \& Technology 18: 240-251.

Krasaekoopt, W.; Bhandari, B.; Deeth, H. Evaluation of encapsulation techniques of probiotics for yogurt. (2003). International Dairy Journal 13(1): 3-13.

Ladjevardi.; Taghi, Mousavi, S.; Mousavi, M. Development of a stable low-fat yogurt gel using functionality of psyllium (Plantago ovata Forsk) husk gum. (2015). Carbohydrate Polymers 125: 272-280.

Latorre, M.; Narvaiz, P.; Rojas, A.; Gerschenson. Effects of gamma irradiation on bio-chemical and physico-chemical parameters of fresh-cut red beet (Beta vulgaris L. var. conditiva) root. (2010). Journal of Food Engineering 98: 178191.

Lyer, R; Tomar, S; Kapila, S; Mani, J. y Singh, R. Probiotic properties of folate producing Streptococcus thermophilus strains. (2010). Food Research International 43:103-110.

Lubbers, S.; Decourcelle, N.; Vallet, N.; Guichard, E. Flavor release and rheology behavior of strawberry fat free stirred yogurt during storage. (2004). Journal Agricultural Food Chemistry 52: 3077-3082.

Moreno, M.; Belen, D.; Matos, A. Degradación de betalainas en remolacha (BETA VULGARIS L). (2002). Revista Científica 12 (2): 1-8.

Ninfali, P.; Angelino, D. Review Nutritional and functional potential of Beta vulgaris cicla and rubra. (2015). Revista Fitoterapia 89: 188-199.

Olson, D.; Aryana J. An excessively high Lactobacillus acidophilus inoculation level in yogurt lowers product quality during storage. (2008). LWT 41: 911-918.

Parra, R. Encapsulación de sábila (aloe vera) y su efecto durante la incubación de yogur. (2014). Revista Cultura científica 1:6673.

Parra, R. Efecto del té verde (Camellia sinensis L.) en las características fisicoquímicas, microbiológicas, proximales y sensoriales de yogurt durante el almacenamiento bajo refrigeración. (2013). Revista @limentech Ciencia y Tecnología Alimentaria 11(1): 56-64. 
Parra, R. Importancia terapéutica y estabilizantes-edulcorantes en la tecnología de yogur. 1 edición. Tunja. (2012). Universidad Pedagógica y Tecnológica de Colombia.

Parra, R. Revisión: Microencapsulación de Alimentos. (2010). Revista Facultad Nacional de Agronomía 63:5669-5684.

Rodriguez, D. Natural foods pigments and colorants. (2016). Current Opinion in Food Science 7:20-26.

Rojas, W.; Chacón, A.; Pineda, M. Características del yogurt batido de fresa derivadas de diferentes proporciones de leche de vaca y cabra. (2007). Agronomía Mesoamericana 18(2): 221-237.

Soriano, J.; Franco, M.; Pelayo, C.; Armella, M.; Yáñez, M.; Guerrero, I. Caracterización parcial del pigmento rojo del fruto de la "jiotilla. (2007). Revista Mexicana de Ingeniería Química 6: 19-25.

Sahan, N.; Yasarb, K.; Hayaloglu, A. Physical, chemical and flavour quality of non-fat yogurt as affected by a $\beta$-glucan hydrocolloidal composite during storage. (2008). Food Hydrocolloids 22: 1291-1297.

Sultana, K.; Godward, G.; Reynolds, N.; Arumugaswamy, R.; Peiris, P.; Kailasapathy, K. Encapsulation of probiotic bacteria with alginate-starch and evaluation of survival in simulated gastrointestinal conditions and in yoghurt. (2000). International Journal of Food Microbiology 62: 47-55.

Zare, F.; Champagne, C.; Simpson, B.; Orsat, V.; Boye, J. Effect of the addition of pulse ingredients to milk on acid production by probiotic and yoghurt starter cultures. (2012). Food Science and Technology 45: 155-160. 